\title{
SHSST-cyclodextrin complex inhibits TGF-ß/Smad3/CTGF to a greater extent than silymarin in a rat model of carbon tetrachloride-induced liver injury
}

\author{
CHENG-HSUN YANG ${ }^{1,2}$, WEI-JEN TING ${ }^{3}$, CHIA-YAO SHEN $^{4}$, HIS-HSIEN HSU ${ }^{5}$, YUEH-MIN LIN ${ }^{6,7}$, \\ SHENG-HUANG CHANG ${ }^{8}$, FUU-JEN TSAI $^{2}$, VISWANADHA VIJAYA PADMA $^{9}$, \\ CHIH-YANG HUANG ${ }^{2,3,10^{*}}$ and YUHSIN TSAI ${ }^{1,2 *}$
}

\begin{abstract}
${ }^{1}$ Graduate Institute of Chinese Medicine; ${ }^{2}$ School of Chinese Medicine; ${ }^{3}$ Graduate Institute of Basic Medical Science, China Medical University, Taichung 40402; ${ }^{4}$ Department of Nursing, Meiho University, Pingtung 91202;

${ }^{5}$ Division of Colorectal Surgery, Mackay Memorial Hospital, New Taipei 10449; ${ }^{6}$ Department of Pathology, Changhua Christian Hospital, Changhua 50006; ${ }^{7}$ Department of Medical Technology, Jen-Teh Junior College of Medicine, Nursing and Management, Miaoli 35664; ${ }^{8}$ Department of Laboratory, Tsaotun Psychiatric Center, Ministry of Health and Welfare, Nantou 54249, Taiwan, R.O.C.; ${ }^{9}$ Department of Biotechnology, Bharathiar University, Coimbatore 641046, India;

${ }^{10}$ Department of Health and Nutrition Biotechnology, Asia University, Taichung 41354, Taiwan, R.O.C.
\end{abstract}

Received April 25, 2014; Accepted December 12, 2014

DOI: $10.3892 / \mathrm{mmr} .2015 .4190$

\begin{abstract}
At present, cirrhosis is an incurable liver disease. Transforming growth factor $\beta$ (TGF- $\beta$ ) is important in myofibroblast induction during the cirrhosis initiation process. The current approach in the development of hepatoprotective drugs depends on TGF- $\beta$ inhibition. San Huang Shel Shin Tang (SHSST) is a traditional herbal decoction able to exert a protective effect on the liver, however, similar to silymarin, it is limited by its hydrophobicity. In the present study, SHSST was modified with $\beta$-cyclodextrin to form a hydrophilic complex, which improved its bioavailability. In the carbon tetrachloride-induced acute injury animal model, the effects of pretreatment with silymarin, baicalein, SHSST and the SHSST- $\beta$-CD-complex (SHSSTc) at a low and high dose were assessed. The biopsy results revealed marked liver protection following treatment with silymarin, baicalein and SHSST and these effects were improved further
\end{abstract}

Correspondence to: Professor Chih-Yang Huang, Graduate Institute of Basic Medical Science, China Medical University, No. 91 Hsueh-Shih Road, Taichung 40402, Taiwan, R.O.C.

E-mail: cyhuang@mail.cmu.edu.tw

Dr Yuhsin Tsai, School of Chinese Medicine, China Medical University, No. 91 Hsueh-Shih Road, Taichung 40402, Taiwan, R.O.C.

E-mail: yhtsai@mail.cmu.edu.tw

*Contributed equally

Key words: transforming growth factor $\beta$, San Huang Shel Shin Tang, carbon tetrachloride-induced acute injury, silymarin following pretreatment with SHSSTc. Protein analysis demonstrated that the hepatoprotective effects of silymarin occurred through inhibition of the TGF- $\beta /$ Smad-3/connective tissue growth factor (CTGF) signaling pathway. SHSSTc exerted the same protective mechanism, however, SHSSTc suppressed CTGF level to a greater extent compared with the groups treated with SHSST or silymarin. Only pretreatment with SHSST and SHSSTc exhibited partial enhancement in the expression of proteins involved in the regulation of liver regeneration, including extracellular-signal-regulated kinase 5, phospho-nuclear factor of activated T cells 3 and phospho-GATA4.

\section{Introduction}

In the Asian population, non-alcoholic fatty liver disease is an increasing public health concern, which encompasses fibrosis, cirrhosis and hepatocarcinoma (1-4). Owing to this, it is necessary to develop a novel drug, which is more efficient and lowers the necessary dosage in order to treat this disease and prevent side effects.

The mechanism of carbon tetrachloride $\left(\mathrm{CCl}_{4}\right)$-induced liver acute injury and fibrosis is hypothesized to act through the trichloromethyl free radical $\left(\mathrm{CCl}^{\circ}\right)$ produced from its metabolism by the cytochrome P450 enzyme (5). The metabolic products of the trichloromethyl free radical are converted to the trichloromethyl peroxy radical (CCl3OO') (6). Liver fibrosis is associated with an activated inflammatory response through expression of pro-inflammatory cytokines (7). Interleukin (IL)-6 is a cytokine that is able to trigger the inflammatory cascade and cell death in hepatocytes. In addition, connective tissue growth factor (CTGF) level is increased in patients with liver cirrhosis $(8,9)$. TGF- $\beta$ is a key mediator of cirrhosis $(10,11)$. Anti-cirrhosis drugs are able to prevent 
and reverse the process of fibrosis through the inhibition of TGF- $\beta$ and CTGF.

Silymarin is a promising treatment against $\mathrm{CCl}_{4}$-induced acute liver injury. Silymarin is a herbal liver-protective drug with four flavonolignan isomers, including 60-70\% silybin, $20 \%$ silychristin, $10 \%$ silydianin and 5\% isosilybin $(12,13)$. San Huang Shel Shin Tang (SHSST) is also a cocktail-like traditional herbal decoction used for liver protection in China. SHSST is composed of 50\% Rheum officinale Baill, $25 \%$ Scutellaria baicalnsis Geprgi and 25\% Coptis chinensis Franch. Rheum has been reported to have a liver protective effect folowing $\mathrm{CCl}_{4}$-induced injury in rats $(14,15)$. Scutellaria and Coptis were also identified to have similar hepatoprotective effects in acute hepatotoxicity (16-18). The coinciding liver protective effects between Rheum officinale, Scutellaria baicalnsis and Coptis chinensis are due to their shared bioactive compounds, including potent flavonoids, such as baicalein (19-23).

SHSST and silymarin are potential liver protection drugs, but are limited by poor water solubility and poor bioavailability (30\%) (24-26). A formulation approach is necessary for increasing the solubility of these drugs. $\beta$-cyclodextrin $(\beta-C D)$ modification is able to increase the solubility and spectral properties of the hydrophobic drugs, without altering their intrinsic ability to permeate the cell membrane (27-29). Thus, SHSST was modified to a SHSST- $\beta$-CD-complex (SHSSTc) and evaluated in the present study.

Janus kinase (JAK) phosphorylation is mediated through IL-6 activation (30). Furthermore, signal transducer and activator of transcription 3 (STAT3) is a downstream protein of JAK and regulates the hepatocyte regeneration (30). In addition, extracellular-signal-regulated kinase 5 (ERK5) and nuclear factor of activated T cells (NFAT) are also implicated in liver regeneration $(31,32)$. In the present study, silymarin and baicalein were used in the evaluation of inflammation-regulated IL- 6 expression and fibrosis-regulated TGF- $\beta$ expression in $\mathrm{CCl}_{4}$-induced acute injury. Additionally, proteins involved in the regulation of liver regeneration were also analyzed in association with SHSSTc-mediated liver protection effects.

\section{Materials and methods}

Preparation of SHSSTc and drug treatment. The SHSST complex with $\beta$-CD was prepared by co-precipitation. $\beta-C D$ $(70.0 \mathrm{~g})$ was dissolved in distilled water $(85 \mathrm{ml})$ at $70^{\circ} \mathrm{C}$ in a water bath for $1 \mathrm{~h}$. SHSST (10.0 g) in $15 \mathrm{ml}$ ethanol was slowly added to the $\beta$-CD solution with continuous agitation for $6 \mathrm{~h}$. Following this, $40 \mathrm{ml}$ of ethanol was added dropwise to regulate the solubility of the hydrophobic solute in the $\beta-\mathrm{CD}$ solution. Subsequently, the solution was refrigerated overnight at $4^{\circ} \mathrm{C}$. The precipitated SHSSTc (SHSST: $\beta-C D=1: 9$ in weight) was recovered by filtration and washed with ethanol to remove unencapsulated SHSST. This residue was dried in a vacuum at $-20^{\circ} \mathrm{C}$ for $48 \mathrm{~h}$. The final powder was stored at $4^{\circ} \mathrm{C}$ until use.

Silymarin and baicalein were purchased from Sigma-Aldrich (St. Louis, MO, USA). The silymarin, baicalein, SHSST and SHSSTc stock solutions for treatments were prepared by dissolving in distilled deionized water at
$100 \mathrm{mg} / \mathrm{ml}$ each. $\mathrm{CCl}_{4}$ was dissolved in olive oil at a concentration of $4 \% \mathrm{v} / \mathrm{v}$.

High performance liquid chromatography (HPLC) analysis. Baicalein, SHSST and SHSSTc were dissolved in the mobile phase solution $(69 \% 60 \mathrm{mM}$ phosphoric acid water solution and $31 \%$ acetonitrile, $\mathrm{pH} 3.2$ ) and analyzed by HPLC with ultraviolet detection, using a C-18 column (Mightysil RP-18 GP column; Kanto Chemical Co., Iwiki, Japan) and the flow rate was $1.0 \mathrm{ml} / \mathrm{min}$. Baicalein was detected using a UV-VIS detector (SPD 20A/20AV; Shimadzu Corporation, Kyoto, Japan) at an absorbance of $279 \mathrm{~nm}$.

Animal model. A total of 42 Sprague-Dawley rats were purchased from BioLASCO Taiwan Co., Ltd (Taipei, Taiwan) and divided into the following seven groups $(n=6)$ : Control (group I), $\mathrm{CCl}_{4}$ intraperitoneal injection treatment (group II), $\mathrm{CCl}_{4}$ intraperitoneal injection combined with silymarin (100 mg/kg/day) oral treatment (group III), $\mathrm{CCl}_{4}$ intraperitoneal injection combined with baicalein $(30 \mathrm{mg} / \mathrm{kg} /$ day $)$ oral treatment (group IV), $\mathrm{CCl}_{4}$ intraperitoneal injection combined with SHSST (30 mg/kg/day) oral treatment (group V), $\mathrm{CCl}_{4}$ intraperitoneal injection combined with sSHSSTc (30 mg/kg/day) oral treatment (group VI) and $\mathrm{CCl}_{4}$ intraperitoneal injection combined with SHSSTc $(300 \mathrm{mg} / \mathrm{kg} /$ day) oral treatment (group VII). After 4 weeks of pretreatment, the $\mathrm{CCl}_{4}$ intraperitoneal injection $(0.2 \mathrm{ml} / \mathrm{kg})$ was applied to all groups with the exception of the control group. Subsequently, the liver tissue was collected from all rats $48 \mathrm{~h}$ after $\mathrm{CCl}_{4}$ intraperitoneal injection. The study was approved by the ethics committee of the Institutional Animal Care and Use Committee (100-4-B) of the China Medical University (Taichung, Taiwan).

Hematoxylin and eosin $(H \& E)$ staining. The livers of rats in each group were soaked in $10 \%$ formalin, dehydrated through graded alcohols and embedded in paraffin wax. Subsequently, the $0.2 \mu \mathrm{m}$-thick paraffin sections were cut into slices from these paraffin-embedded tissue blocks. The tissue sections were deparaffinized by immersing in xylene and rehydrated. All slices were stained with $\mathrm{H} \& \mathrm{E}$ and then rinsed with water. Each slide was dehydrated through graded alcohols. Finally, the samples were soaked in xylene twice. Photomicrographs were obtained using a Zeiss Axiophot microscope (Carl Zeiss Inc., Oberkochen, Germany).

Masson's trichrome staining. The livers of rats in each group were soaked in $10 \%$ formalin, dehydrated through graded alcohols and embedded in paraffin wax. Subsequently, the $0.2 \mu \mathrm{m}$-thick paraffin sections were cut into slices from these paraffin-embedded tissue blocks. The tissue sections were deparaffinized by immersing in xylene and rehydrated. The samples were then stained with Masson's trichrome staining to investigate histological and fibrotic alterations in the liver. Photomicrographs were obtained using a Zeiss Axiophot microscope.

Tissue protein extraction. Liver tissue extracts of six rats in each group were obtained by homogenizing in a lysis buffer (0.05 M Tris- $\mathrm{HCl}$, pH 7.4, 0.15 M NaCl, 0.25\% deoxycholic acid, 1\% NP-40 and 1 mM EDTA) at a ratio of $100 \mathrm{mg}$ 

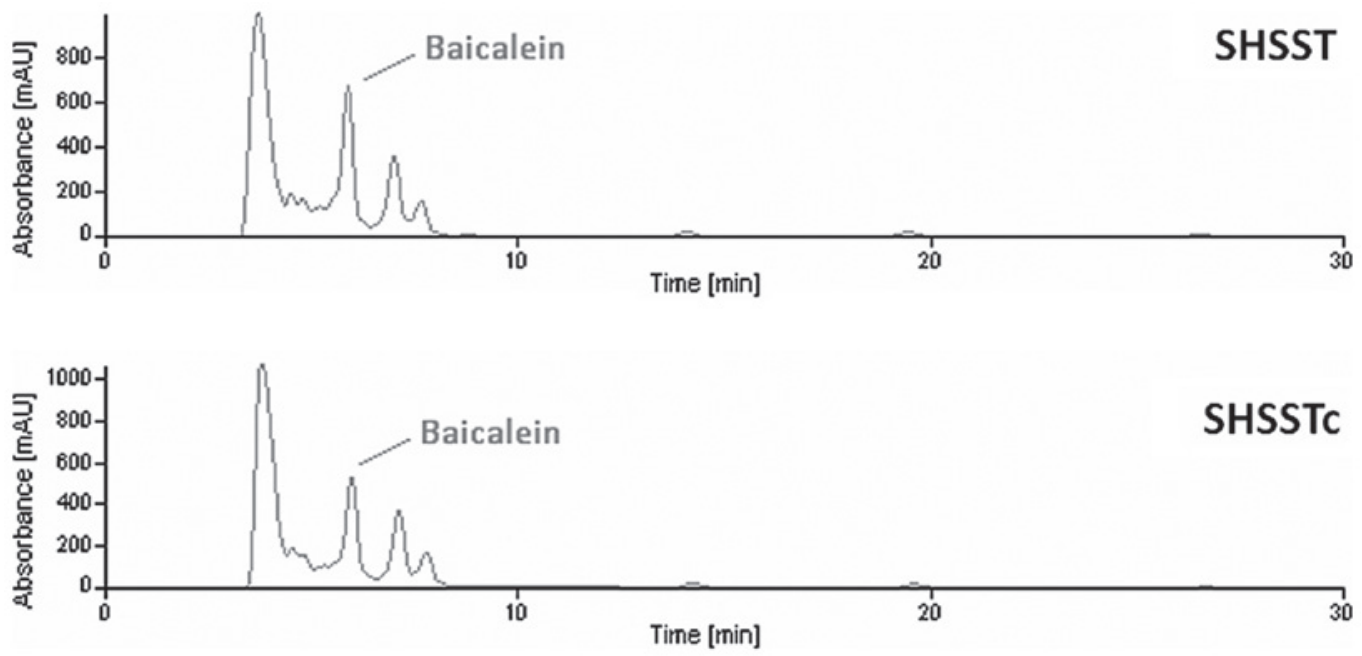

Figure 1. High performance liquid chromatography analysis of baicalein in SHSST and SHSSTc. Baicalein is a bioactive compound that exists in SHSST and SHSSTc with a maximum absorbance at a wavelength of $279 \mathrm{~nm}$. The mobile phase elution rate was set at $1 \mathrm{ml} / \mathrm{min}$ and the retention of baicalein was $5.907 \mathrm{~min}$. SHSST contained $54.5 \mathrm{mg} / \mathrm{g}$ baicalein and SHSSTc contained $4.6 \mathrm{mg} / \mathrm{g}$ baicalein. SHSST, San Huang Shel Shin Tang; SHSSTc; SHSST- $\beta$-cyclodextrin-complex.

tissue $/ 1 \mathrm{ml}$ buffer. The homogenates were placed on ice and then centrifuged at $18,900 \mathrm{x}$ g for $40 \mathrm{~min}$. The supernatants were collected and stored at $-80^{\circ} \mathrm{C}$ for further experiments.

Western blot analysis. The protein concentration of liver tissue extracts was determined using the Lowry protein assay. Protein samples were separated using a 12\% SDS polyacrylamide gel electrophoresis with a constant voltage of $75 \mathrm{~V}$ for $2 \mathrm{~h}$. The proteins were then transferred onto Hybond-C membranes (GE Healthcare, Amersham, UK) at 50 volts for $3 \mathrm{~h}$. Polyvinylidene difluoride membranes were incubated in 3\% bovine serum albumin in Tris-buffered saline (Sigma-Aldrich). Primary antibodies, including goat polyclonal immunoglobulin G (IgG) IL-6 (cat no. SC-1266; Santa Cruz Biotechnology, Inc., Santa Cruz, CA, USA), p-JAK (cat no. SC-21870; Santa Cruz Biotechnology, Inc.), rabbit polyclonal IgG STAT-3 (cat no. SC-483; Santa Cruz Biotechnology, Inc.), mouse monoclonal $\operatorname{IgG}_{2 \mathrm{a}} \alpha$-tubulin (cat no. SC-5286; Santa Cruz Biotechnology, Inc.), goat polyclonal IgG ERK5 (cat no. SC-1284; Santa Cruz Biotechnology, Inc.), rabbit polyclonal IgG p-GATA4 (cat no. SC-32823; Santa Cruz Biotechnology, Inc.), rabbit polyclonal IgG Smad-3 (cat no. SC-8332; Santa Cruz Biotechnology, Inc.), rabbit monoclonal IgG NFAT-3 (cat no. 2188; Cell Signaling Technology, Inc., Danvers, MA, USA), rabbit monoclonal TGF- $\beta$ (cat no. 3709, Cell Signaling Technology, Inc.) and goat polyclonal IgG CTGF (cat no. SC-14939, Santa Cruz Biotechnology, Inc.) were added to the membranes for binding to the target proteins. Finally, horseradish peroxidase-labeled antibodies (donkey anti-goat IgG-HRP, sc-2020; goat anti-mouse IgG-HRP, sc-2005; goat anti-rabbit IgG-HRP, sc-2004; Santa Cruz Biotechnology, Inc.) were used and images were captured using a LAS-4000 camera (GE Healthcare).

Statistical analysis. Data are expressed as the mean \pm standard deviation of three independent experiments. Statistical analysis was performed using a one-way analysis of variance. For paired samples, Student's t-test was applied. Statistical analysis was conducted using SigmaPlot, version 10.0 (Systat
Software, Inc., San Jose, CA, USA) and $\mathrm{P}<0.05$ was considered to indicate a statistically significant difference.

\section{Results}

In the process of precipitating SHSSTc (SHSST: $\beta-C D=1: 9$ weight), washing and filtration is necessary to unencapsulate SHSST. The $\beta$-CD complex modification increased the formula weight of the SHSSTc. The bioactive components, including baicalein, were compared between SHSSTc and SHSST. HPLC analysis revealed that SHSST contained $54.5 \mathrm{mg} / \mathrm{g}$ baicalein and SHSSTc contained $4.6 \mathrm{mg} / \mathrm{g}$ baicalein (Fig. 1). This result demonstrated that the concentration of baicalein present in SHSST was 11.8 times greater than that in SHSSTc.

The liver biopsy with H\&E staining is shown in (Fig. 2). $\mathrm{CCl}_{4}$ induced cell death surrounding the microvascular and caused vacuole-like structures. The hepatocytes were protected with a complete structure in the groups pretreated with silymarin, baicalein, SHSST, SHSSTc (low dose) and SHSSTc (high dose). Masson's trichrome staining is useful in the detection of cirrhosis with collagen indicated in blue. In the $\mathrm{CCl}_{4}$-induced fibrosis group, marked collagen accumulation was observed. The collagen accumulation decreased in the silymarin, baicalein and SHSST treatment groups. In addition, collagen accumulation was undetectable in the high dose and low dose SHSSTc treatment groups (Fig. 2).

IL-6 signaling pathway analysis revealed an increase in IL-6 protein level after $48 \mathrm{~h}$ of $\mathrm{CCl}_{4}$-induced inflammation (Fig. 3). However, IL-6 expression decreased significantly following pretreatment with silymarin and partially decreased following pretreatment with baicalein, SHSST and SHSSTc. After $48 \mathrm{~h} \mathrm{CCl}_{4}$-induced inflammation, p-JAK expression was partially increased, however, no suppression was observed in the groups pretreated with silymarin, baicalein, SHSST and SHSSTc. The STAT3 expression level was only decreased in the group pretreated with silymarin after $48 \mathrm{~h}$ of $\mathrm{CCl}_{4}$-induced inflammation.

The levels of TGF- $\beta$, Smad- 3 and CTGF were increased $48 \mathrm{~h}$ after $\mathrm{CCl}_{4}$-induced acute injury (Fig. 4). Following 


\section{$\mathrm{CCl}_{4}$}

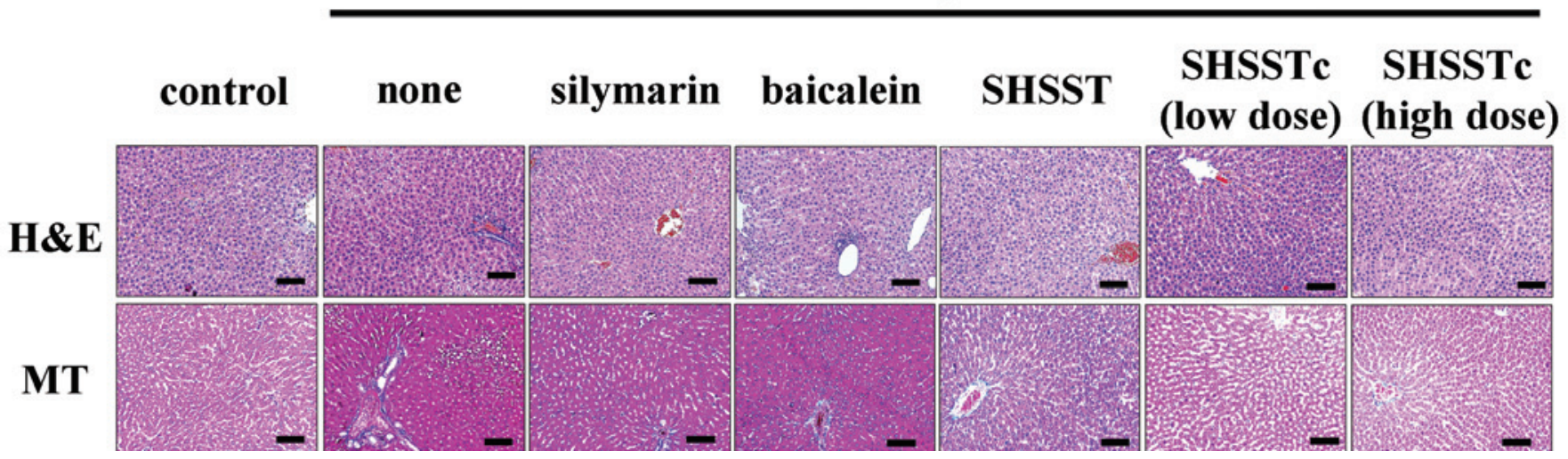

Figure 2. H\&E stain and MT stain of liver slides. The nucleus of cells was stained blue and the cytosol was stained pink in the H\&E staining assay. Blue indicates fibrosis with collagen accumulation and pink indicates normal cells in the MT staining assay. Scale bar=100 $\mu$ m. SHSST, San Huang Shel Shin Tang; SHSSTc; SHSST- $\beta$-cyclodextrin-complex; $\mathrm{CCl}_{4}$, carbon tetrachloride; H\&E, hematoxylin and eosin; MT, Masson's trichrome.

A

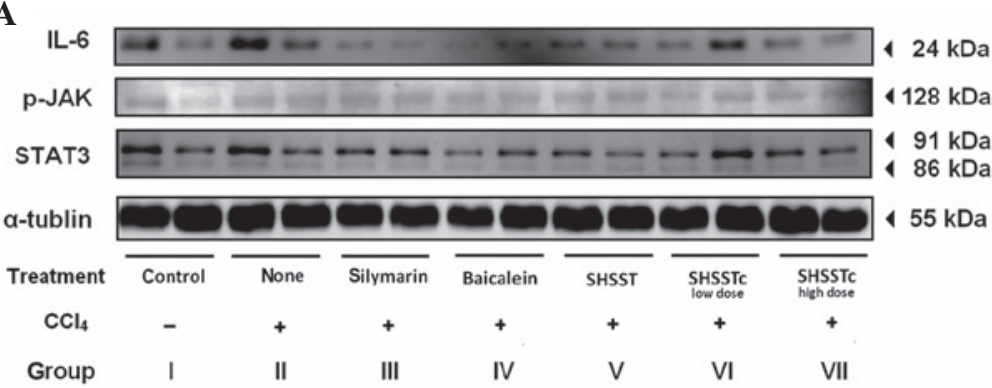

C

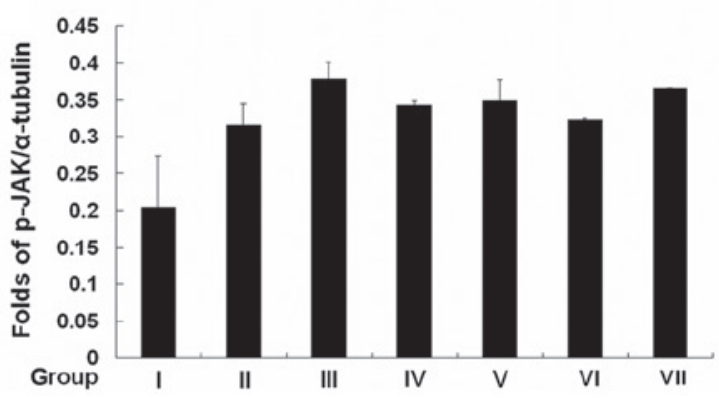

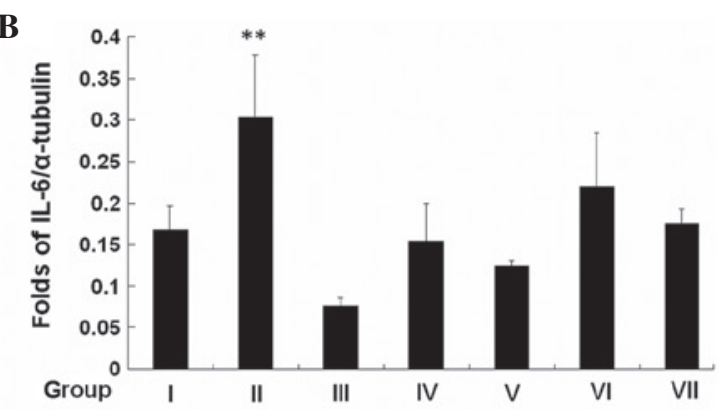

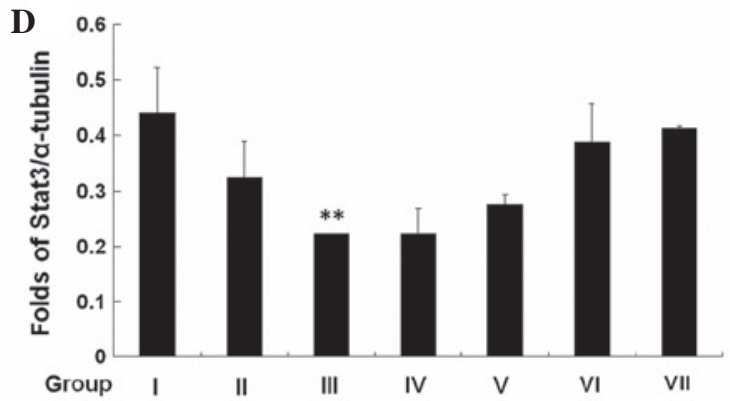

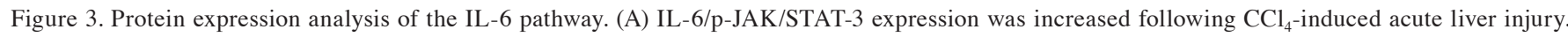
Pretreatment with silymarin, baicalein, SHSST, SHSSTc at a low and high dose was able to partially reduce the protein expression of the IL-6 pathway. (B) Normalized protein expression of IL-6 with $\alpha$-tubulin. (C) Normalized protein expression of p-JAK with $\alpha$-tubulin. (D) Normalized protein expression of STAT-3 with $\alpha$-tubulin. ${ }^{* *} \mathrm{P}<0.05$, compared with group I. IL-6, interleukin-6; SHSST, San Huang Shel Shin Tang; SHSSTc; SHSST- $\beta$-cyclodextrin-complex; STAT-3, signal transducer and activator of transcription 3; $\mathrm{CCl}_{4}$, carbon tetrachloride; JAK, Janus kinase.

pretreatment with silymarin, the TGF- $\beta$ signaling pathway was significantly inhibited in the SHSSTc high and low dose pretreatment groups. SHSSTc exerted the same protective mechanism and exhibited greater suppression of the CTGF level compared with SHSST and silymarin treatment. Pretreatment with baicalein and SHSST was also able to partially reduce the protein level of TGF- $\beta$, Smad-3 and CTGF.

Proteins involved in the regulation of hepatocyte regeneration, including ERK5, p-NFAT-3 and p-GATA-4 were analyzed (Fig. 5). The $\mathrm{CCl}_{4}$-induced injury did not stimulate regeneration in the liver without pretreatment with any drugs. The pretreatment of silymarin and baicalein was able to increase ERK5 and the expression of p-NFAT-3. p-GATA-4 expression was increased in the liver of the SHSSTc low dose pretreatment group and partially increased in the silymarin, baicalein and SHSST pretreatment groups.

\section{Discussion}

In the present study, hydrophobic SHSST was altered to hydrophilic SHSSTc through $\beta$-CD complex modification. Baicalein was selected as the standard used in the bioactive ingredient for HPLC analysis of SHSST and SHSSTc. The results demonstrated that SHSST contained 11.8 times more baicalein as SHSSTc at the same weight. The protective effects of pretreatment with SHSSTc (low dose and high dose) were similar to silymarin, baicalein and SHSST in the $\mathrm{CCl}_{4}$-induced acute liver injury. 
A

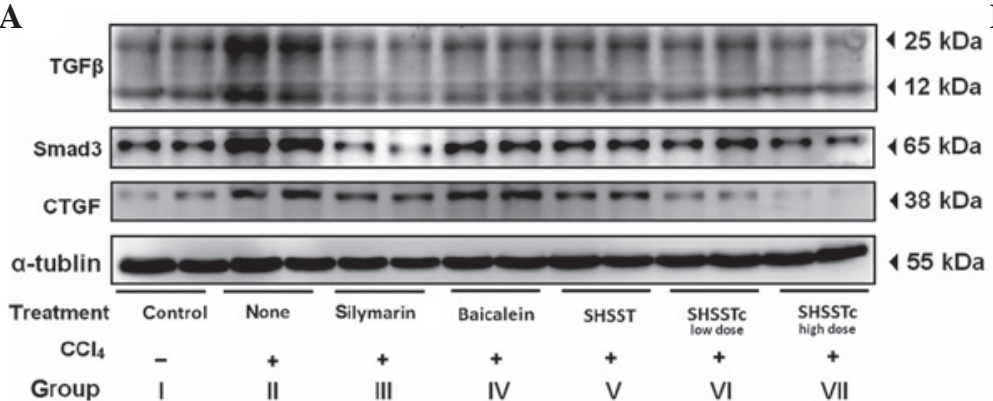

C

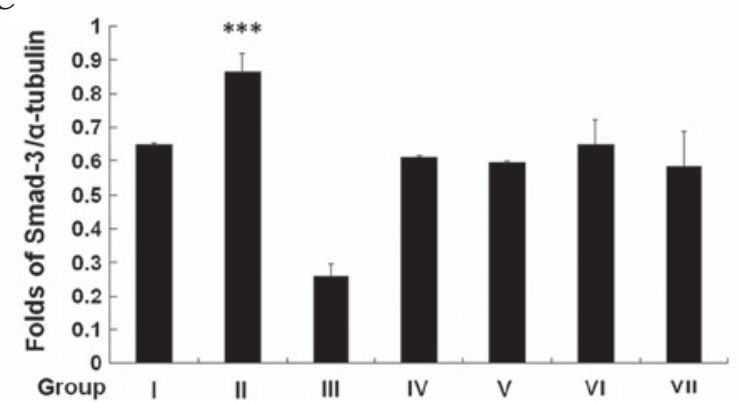

B

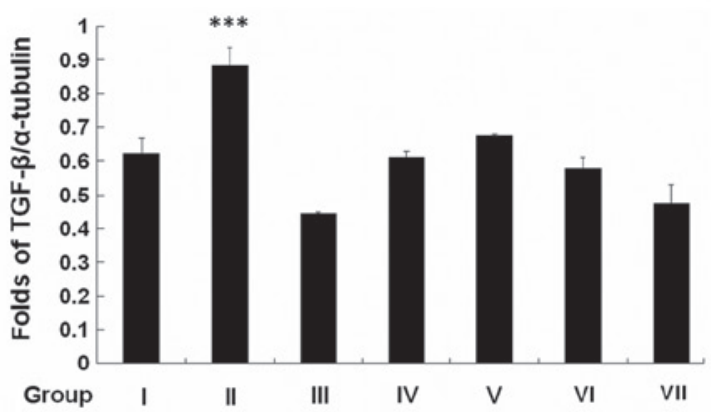

D

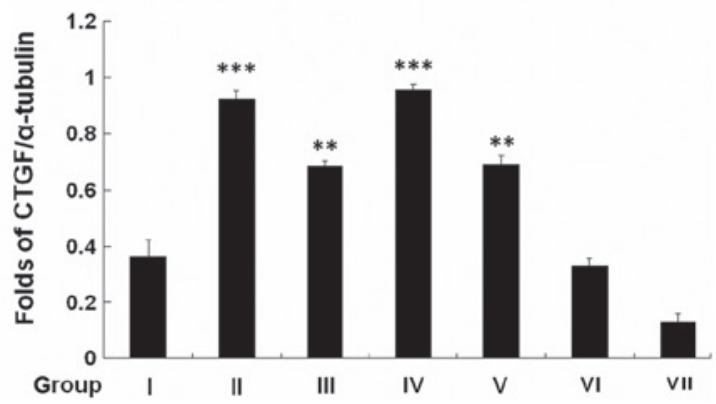

Figure 4. Protein expression analysis of the TGF- $\beta$ pathway. (A) TGF- $\beta /$ Smad-3/CTGF expression was increased following CCl ${ }_{4}$-induced acute liver injury. Pretreatment with silymarin, baicalein, SHSST, SHSSTc at a low dose and high dose was able to reduce the protein expression of the TGF- $\beta$ pathway. (B) Normalized protein expression of TGF- $\beta$ with $\alpha$-tubulin. (C) Normalized protein expression of Smad-3 with $\alpha$-tubulin. (D) Normalized protein expression of CTGF with $\alpha$-tubulin. ${ }^{* *} \mathrm{P}<0.05$ and ${ }^{* * *} \mathrm{P}<0.001$ compared with group I. TGF, transforming growth factor; CTGF, connective tissue growth factor; SHSST, San Huang Shel Shin Tang; SHSSTc; SHSST- $\beta$-cyclodextrin-complex; $\mathrm{CCl}_{4}$, carbon tetrachloride.

A

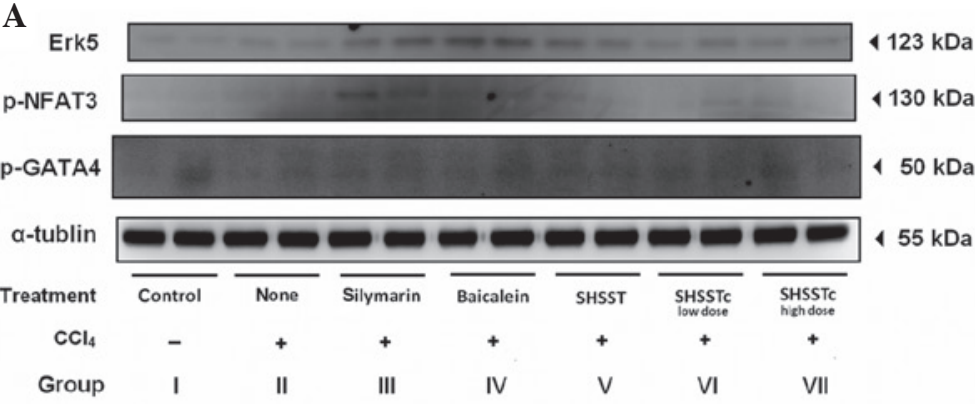

C

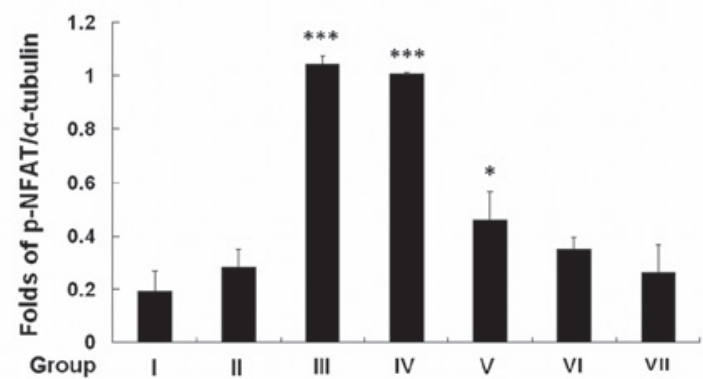

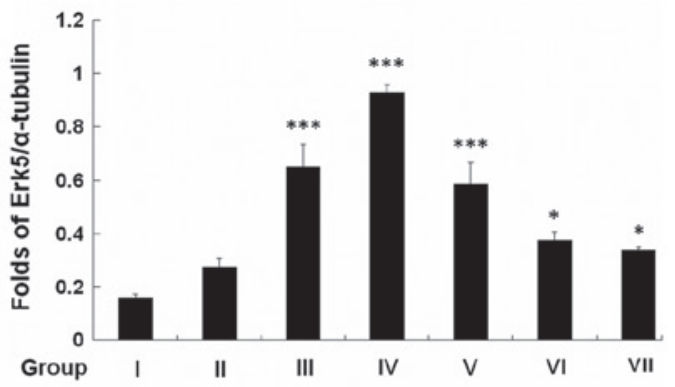

D

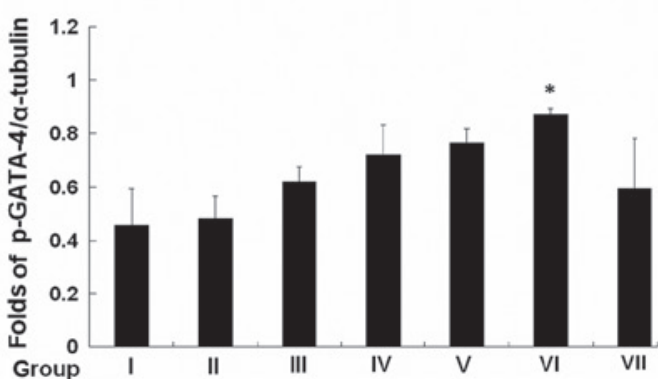

Figure 5. Protein expression analysis of liver regeneration. (A) ERK5, p-NFAT-3 and p-GATA-4 expression was not altered following CCl4-induced acute liver injury at $48 \mathrm{~h}$. Pretreatment with silymarin, baicalein and SHSST increased the protein expression of ERK5 and p-GATA-4. (B) Normalized protein expression of ERK5 with $\alpha$-tubulin. (C) Normalized protein expression of p-NFAT-3 with $\alpha$-tubulin. (D) Normalized protein expression of p-GATA-4 with $\alpha$-tubulin. ${ }^{*} \mathrm{P}<0.01$ and ${ }^{* * * *} \mathrm{P}<0.001$ compared with group I. SHSST, San Huang Shel Shin Tang; SHSSTc; SHSST- $\beta$-cyclodextrin-complex; NFAT, nuclear factor of activated T-cells; $\mathrm{CCl}_{4}$, carbon tetrachloride 4 .

Hepatocyte renewal in mild inflammation is mediated through IL-6 and downstream activation of JAK/STAT3 (33). In the present study, $\mathrm{CCl}_{4}$-induced acute injury increased the expression of IL-6. Pretreatment with hepatoprotective drugs, including silymarin, baicalein, SHSST and SHSSTc, reduced the protein level of IL-6. However, alterations in p-JAK expression were not detectable in all drug pretreatment groups due to the short half-life of p-JAK. A previous study identified that the half-life of JAK activation was $<20 \mathrm{sec}(34)$. However, downstream STAT3 protein expression in each group was similar 
to that of IL-6. Although the activation of STAT3 is regulated during hepatocyte regeneration, peroxisome proliferator-activated receptor leads to the degradation of STAT3 through hepatic oxidative stress and loses its original function (30).

In cirrhosis, TGF- $\beta$ is important as a negative regulator of proliferation and an inducer of CTGF synthesis $(35,36)$. Several approaches aim at inhibition of TGF- $\beta$ function as a priority target for the development of antifibrotic drugs. In the present study, $\mathrm{CCl}_{4}$-induced acute injury caused TGF- $\beta /$ Smad-3/CTGF activation, which was decreased significantly by pretreatment with silymarin and SHSSTc (high dose). SHSSTc exerted a greater suppression on CTGF level than SHSST and silymarin. The results confirmed the antifibrotic effects of silymarin through inhibition of TGF- $\beta /$ Smad-3/CTGF and also suggested the SHSSTc exhibited a more significant antifibrotic effect than silymarin (37).

ERK5 is activated by TGF- $\beta$ in hepatocytes, which also regulates the proliferation and migration of hepatic stellate cells $(38,39)$. In the present study, all pretreated groups exhibited partially enhanced ERK5 expression (Fig. 5). The increase in p-NFAT expression levels only occurred in the silymarin and baicalein groups and the lack of NFAT activation may cause incomplete liver regeneration (32). In addition, the development of the mammalian liver is dependent on GATA-4 activation (40). However, GATA-4 phosphorylation was only induced in the SHSSTc low dose treatment group.

In conclusion, the $\beta$-CD complex modification of SHSST promoted the water solubility and increased the bioavailability of SHSST. Thus, the dose necessary for original SHSST in cirrhosis therapy can be reduced at least 10 times through using SHSSTc. In addition, SHSSTc exerts stronger antifibrotic effects than silymarin and baicalein and acts through the inhibition of the TGF- $\beta /$ Smad-3/CTGF signaling pathway similarly to silymarin and baicalein.

\section{Acknowledgements}

This study was supported in part by the Taiwan Ministry of Health and Welfare Clinical Trial and Research Center of Excellence (grant no. MOHW104-TDU-B-212-113002).

\section{References}

1. Loguercio $\mathrm{C}$ and Fredico A: Oxidative stress in viral and alcoholic hepatitis. Free Radic Biol Med 34: 1-10, 2003.

2. Vitaglione P, Morisco F, Caporaso N and Fogliano V: Dietary antioxidant compounds and liver health. Crit Rev Food Sci Nutr 44: 575-586, 2004

3. Diehl AM: Cytokine regulation of liver injury and repair. Immunol Rev 174: 160-171, 2000.

4. Marra F, Valente AJ, Pinzani M and Abboud HE: Cultured human liver fat-storing cells produce monocyte chemotactic protein-1. Regulation by proinflammatory cytokines. J Clin Invest 92: 1674-1680, 1993.

5. Basu S: Carbon tetrachloride-induced lipid peroxidation: eicosanoid formation and their regulation by antioxidant nutrients. Toxicology 189: 113-127, 2003.

6. Zira A, Kostidis S, Theocharis S, Sigala F, Engelsen SB, Andreadou I and Mikros E: 1H NMR-based metabonomics approach in a rat model of acute liver injury and regeneration induced by $\mathrm{CCl}_{4}$ administration. Toxicology 303: 115-124, 2013.

7. Ramadori $\mathrm{G}$ and Armbrust T: Cytokines in the liver. Eur J Gastroenterol Hepatol 13: 777-784, 2001.

8. Kugelmas M, Hill DB, Vivian B, et al: Cytokines and NASH: a pilot study of the effects of lifestyle modification and vitamin $\mathrm{E}$. Hepatology 38: 413-419, 2003.
9. Diehl AM, Goodman Z and Ishak KG: Alcohollike liver disease in nonalcoholics. A clinical and histologic comparison with alcohol-induced liver injury. Gastroenterology 95: 1056-1062, 1988.

10. Ramadori G, Rieder H and Knittel T: Biology and pathobiology of sinusoidal liver cells. In: Hepatic Transport and Bile Secretion. Tavoloni N and Berk PD (eds). Raven Press, New York, NY, pp83-102, 1993.

11. Leask A: Focal adhesion kinase: a key mediator of transforming growth factor beta signaling in fibroblasts. Adv Wound Care (New Rochelle) 2: 247-249, 2013.

12. Attama AA, Nzekwe IT, Nnamani PO, Adikwu MU and Onugu CO: The use of solid self-emulsifying systems in the delivery of diclofenac. Int J Pharm 262: 23-28, 2003.

13. Parveen R, Baboota S, Ali J, Ahuja A, Vasudev SS and Ahmad S: Effects of silymarin nanoemulsion against carbon tetrachloride-induced hepatic damage. Arch Pharm Res 34: 767-774, 2011.

14. Wang JB, Zhao HP, Zhao YL, Jin C, Liu DJ, Kong WJ, Fang F, Zhang L, Wang HJ and Xiao XH: Hepatotoxicity or hepatoprotection? Pattern recognition for the paradoxical effect of the Chinese herb Rheum palmatum L. in treating rat liver injury. PLoS One 6: e24498, 2011.

15. Fang F, Wang JB, Zhao YL, Jin C, Kong WJ, Zhao HP, Wang HJ and Xiao XH: A comparative study on the tissue distributions of rhubarb anthraquinones in normal and $\mathrm{CCl}_{4}$-injured rats orally administered rhubarb extract. J Ethnopharmacol 137: 1492-1497, 2011.

16. Chien $\mathrm{CF}, \mathrm{Wu} \mathrm{YT}$ and Tsai TH: Biological analysis of herbal medicines used for the treatment of liver diseases. Biomed Chromatogr 25: 21-38, 2011.

17. Nan JX, Park EJ, Kim YC, Ko G and Sohn DH: Scutellaria baicalensis inhibits liver fibrosis induced by bile duct ligation or carbon tetrachloride in rats. J Pharm Pharmacol 54: 555-563, 2002.

18. Ye X, Feng Y, Tong Y, Ng KM, Tsao S, Lau GK, Sze C, Zhang Y, Tang J, Shen J and Kobayashi S: Hepatoprotective effects of Coptidis rhizoma aqueous extract on carbon tetrachloride-induced acute liver hepatotoxicity in rats. J Ethnopharmacol 124: 130-136, 2009.

19. Püssa T, Raudsepp P, Kuzina K and Raal A: Polyphenolic composition of roots and petioles of Rheum rhaponticum L. Phytochem Anal 20: 98-103, 2009.

20. Wang CZ, Calway TD, Wen XD, Smith J, Yu C, Wang Y, Mehendale SR and Yuan CS: Hydrophobic flavonoids from Scutellaria baicalensis induce colorectal cancer cell apoptosis through a mitochondrial-mediated pathway. Int J Oncol 42: 1018-1026, 2013

21. Liu L and Chen Z: Analysis of four alkaloids of Coptis chinensis in rat plasma by high performance liquid chromatography with electrochemical detection. Anal Chim Acta 737: 99-104, 2012.

22. Hsu SC, Lin JH, Weng SW, Chueh FS, Yu CC, Lu KW, Wood WG and Chung JG: Crude extract of Rheum palmatum inhibits migration and invasion of U-2 OS human osteosarcoma cells by suppression of matrix metalloproteinase-2 and -9 . Biomedicine 3 : 120-129, 2013

23. Hsu SC and Chung JG: Anticancer potential of emodin. Biomedicine 2: 108-116, 2012.

24. Madaus R, Halbach G and Trost W: Salt of silymarin group with aminopolyhydroxy alcohols. US Patent 3994925A. Filed January 21, 1974; issued November 30, 1976.

25. Comoglio A, Tomasi A, Malandrino S, Poli G and Albano E: Scavenging effect of silipide, a new silybin-phospholipid complex, on ethanol-derived free radicals. Biochem Pharmacol 50: 1313-1316, 1995.

26. Giacomelli S, Gallo D, Apollonio P, Ferlini C, Distefano M, Morazzoni P, Riva A, Bombardelli E, Mancuso S and Scambia G: Silybin and its bioavailable phospholipids complex (IdB 1016) potentiate in vitro and in vivo the activity of cisplatin. Life Sci 70: 1447-1459, 2002.

27. Tsai YS, Tsai HH, Wu CP and Tsai FJ: Preparation, characterisation and activity of the inclusion complex of paeonol with $\beta$-cyclodextrin. Food Chem 120: 837-841, 2010.

28. Yuan C, Jin Z, Xu X, Zhuang $\mathrm{H}$ and Shen W: Preparation and stability of the inclusion complex of astaxanthin with hydroxypropyl- $\beta$-cyclodextrin. Food Chem 109: 264-268, 2008.

29. Vyas A, Saraf S and Saraf S: Cyclodextrin based novel drug delivery systems. J Incl Phenom Macrocycl Chem 62: 23-42, 2008. 
30. Kim JH, Qu A, Reddy JK, Gao B and Gonzalez FJ: Hepatic oxidative stress activates the Gadd45b gene via degradation of the transcriptional repressor STAT3. Hepatology 59: 695-704, 2014.

31. Li Z, Cheng Z, Wang G, Hao X, Zhang L and Xu C: 6 Paths of ERK5 signaling pathway regulate hepatocyte proliferation in rat liver regeneration. Indian J Biochem Biophys 49: 165-172, 2012.

32. Pierre KB, Jones CM, Pierce JM, Nicoud IB, Earl TM and Chari RS: NFAT4 deficiency results in incomplete liver regeneration following partial hepatectomy. J Surg Res 154: 226-233, 2009.

33. Ray S, Ju X, Sun H, Finnerty CC, Herndon DN and Brasier AR: The IL-6 trans-signaling-STAT3 pathway mediates ECM and cellular proliferation in fibroblasts from hypertrophic scar. J Invest Dermatol 133: 1212-1220, 2013.

34. Giese B, Au-Yeung CK, Herrmann A, Diefenbach S, Haan C, Küster A, Wortmann SB, Roderburg C, Heinrich PC, Behrmann I and Müller-Newen G: Long term association of the cytokine receptor gp130 and the Janus kinase Jak1 revealed by FRAP analysis. J Biol Chem 278: 39205-39213, 2003.
35. Gressner AM, Weiskirchen R, Breitkopf K amd Dooley S: Roles of TGF- $\beta$ in hepatic fibrosis. Front Biosci 7: d793-d807, 2002.

36. Bauer S, Eisinger K, Wiest R, Karrasch T, Scherer MN, Farkas S, Aslanidis C and Buechler C: Connective tissue growth factor level is increased in patients with liver cirrhosis but is not associated with complications or extent of liver injury. Regul Pept 179: 10-14, 2012.

37. Jeong DH, Lee GP, Jeong WI, Do SH, Yang HJ, Yuan DW, Park HY, Kim KJ and Jeong KS: Alterations of mast cells and TGF- $\beta 1$ on the silymarin treatment for $\mathrm{CCl}(4)$-induced hepatic fibrosis. World $\mathrm{J}$ Gastroenterol 11: 1141-1148, 2005.

38. Marchetti A, Colletti M, Cozzolino AM, Steindler C, Lunadei M, Mancone $\mathrm{C}$ and Tripodi M: ERK5/MAPK is activated by TGF $\beta$ in hepatocytes and required for the GSK-3 $\beta$-mediated Snail protein stabilization. Cell Signal 20: 2113-2118, 2008.

39. Rovida E, Navari N, Caligiuri A, Dello Sbarba P and Marra F: ERK5 differentially regulates PDGF-induced proliferation and migration of hepatic stellate cells. J Hepatol 48: 107-115, 2008.

40. Watt AJ, Zhao R, Li J and Duncan SA: Development of the mammalian liver and ventral pancreas is dependent on GATA4. BMC Dev Biol 7: 37, 2007. 